\title{
INFLUENCE OF THERMAL FATIGUE ON HOT CORROSION \\ OF AN INTERMETALLIC NI-ALUMINIDE COATING
}

\author{
John W. Holmes ${ }^{1}$ and Frank A. McClintock ${ }^{2}$ \\ ${ }^{1}$ Department of Materials Science and Engineering \\ ${ }^{2}$ Department of Mechanical Engineering \\ Massachusetts Institute of Technology \\ Cambridge, Massachusetts 02139
}

\begin{abstract}
The influence of thermal fatigue strain history on the hot corrosion attack of a Ni-aluminide coating was examined. Coatings were applied by pack aluminization to stepped-disk fatigue specimens machined from a monocrystalline Ni-base superalloy (Rene N4). Induction heating of the stepped-disk specimens was used to simulate the severe thermal and strain transients experienced by gas turbine airfoils. Hot corrosion was studied by applying $\mathrm{Na}_{2} \mathrm{SO}_{4}$ to the specimen, and controlling the partial pressures of $\mathrm{O}_{2}, \mathrm{SO}_{2}$ and $\mathrm{SO}_{3}$ in the test atmosphere.

Hot corrosion of the Ni-aluminide coatings was found to be strongly influenced by strain history. After 6000 fatigue cycles, between peak strains of $-0.26 \%$ at $925^{\circ} \mathrm{C}$ and $0.03 \%$ at $650^{\circ} \mathrm{C}$, extensive hot corrosion attack occurred, with $\mathrm{Al}$ and Ni sulfides found throughout the coating. By contrast, only minor surface oxidation of the coating was observed after 6000 cycles between lower peak strains of $-0.16 \%$ at $925^{\circ} \mathrm{C}$ and $0.01 \%$ at $650^{\circ} \mathrm{C}$.

The pronounced dependence of hot corrosion attack on strain history is attributed to cracking of protective surface oxide scales during thermal fatigue cycling, allowing direct interaction between molten $\mathrm{Na}_{2} \mathrm{SO}_{4}$ and the $\mathrm{Ni}$-aluminide coating. This interaction results in an increase in the oxygen ion $\left(\mathrm{O}^{2-}\right)$ activity in the vicinity of the coating/oxide interface, preventing reformation of a protective oxide scale.
\end{abstract}

Superalloys 1988

Edited by S. Reichman, D.N. Duhl,

G. Maurer, S. Antolovich and C. Lund

The Metallurgical Society, 1988 


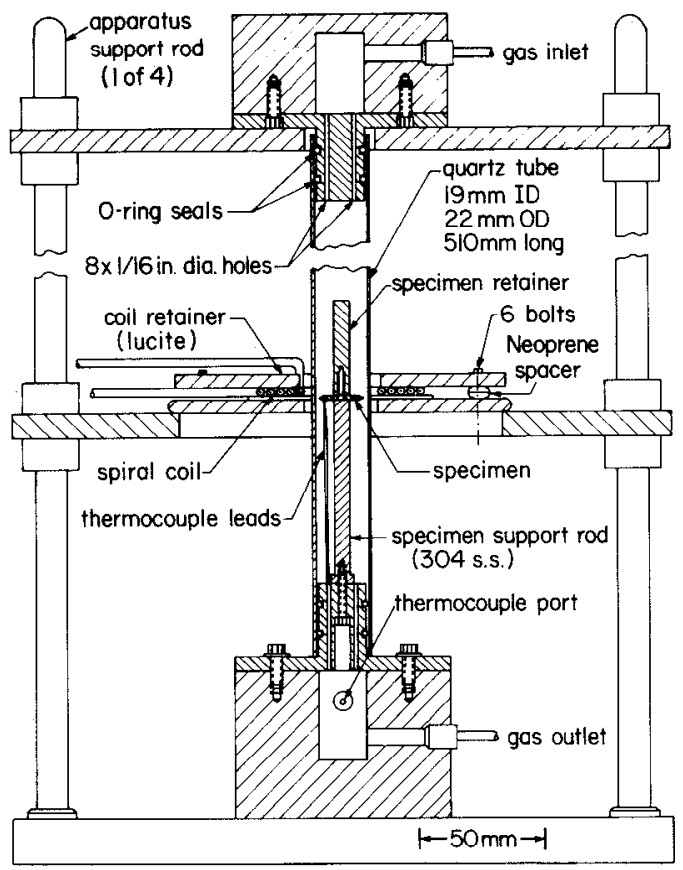

(a)

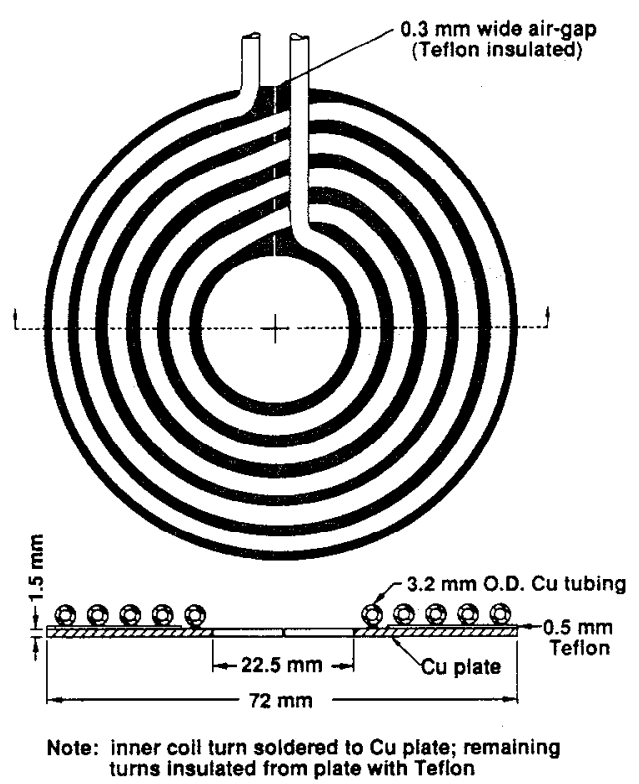

(b)

Figures 3a,b - (a) Schematic of test apparatus. A resistance heater (not shown), which encircled the upper portion of the quartz tube, was used to heat the gas-mixture used in the experiments. (b) Detailed sketch of spiral induction coil. With this coil design, induced currents concentrate along the inner radius of the thin Cu plate; the magnetic flux associated with this current induces eddy currents in the specimen periphery. Further details of the test apparatus are given in Holmes (10).

Test atmosphere. Hot corrosion was studied by coating the specimen periphery with $1.0 \mathrm{mg} / \mathrm{cm}^{2}$ $\mathrm{Na}_{2} \mathrm{SO}_{4}$, and flowing an $\mathrm{O}_{2}-\mathrm{SO}_{2}-\mathrm{SO}_{3}$-argon gas-mixture through the quartz tube containing the specimen. Prior to flowing past the specimen, the initial gas-mixture $\left(20.00 \% \mathrm{O}_{2}, 0.010 \% \mathrm{SO}_{2}\right.$, $79.99 \%$ argon) passed through a $250 \mathrm{~mm}$ long furnace hot-zone, where gas equilibrium was established at $930^{\circ} \mathrm{C}$. A platinum catalyst (6 grams of 80 mesh Pt screen) was used to enhance establishment of equilibrium. Assuming complete equilibrium, the volumetric composition of the gas exiting the hot-zone was: $20.00 \% \mathrm{O}_{2}, 0.0089 \% \mathrm{SO}_{2}, 0.0011 \% \mathrm{SO}_{3}$ and $79.99 \%$ argon. A gas flow rate of $100 \mathrm{~cm}^{3} / \mathrm{min}$ was used in all experiments.

Iemperature and strain history of test specimens. Two sets of experiments were performed in the hot corrosion environment:

(1) isothermal exposure for 100 and $200 \mathrm{hr}$ at $930^{\circ} \mathrm{C}$ and,

(2) thermal fatigue cycling between 450 and $930^{\circ} \mathrm{C}$, for 3000 and 6000 cycles (total test time at $930^{\circ} \mathrm{C}$ was 50 and $100 \mathrm{hr}$, respectively).

The temperature cycle used in the thermal fatigue tests (Fig. 4a) incorporated a rapid 9s heating transient from 450 to $930^{\circ} \mathrm{C}$, followed by a 60 s hold, and cooling to $450^{\circ} \mathrm{C}$ in $30 \mathrm{~s}$. As shown in Fig. 4b, the substrate (and coating) ${ }^{1}$ strain range along low modulus $\langle 100\rangle$ substrate orientations was approximately $60 \%$ higher than that for the stiffer $<110>$ orientations (from the strain limits shown in Fig. $4 \mathrm{~b}, \Delta \varepsilon_{\mathrm{coat}}^{\mathrm{mech}}=0.29 \%$ at $<100>$ orientations vs. $\Delta \varepsilon_{\mathrm{coat}}^{\mathrm{mech}}=0.17 \%$ at $\langle 110\rangle$ orientations).

\footnotetext{
${ }^{1}$ Note that since the thin coating provides negligible constraint to the much stiffer substrate, the total in-plane strain history of the coating equals the total in-plane strain history of the substrate periphery. Furthermore, since the Ni-aluminide coating studied has a thermal expansion coefficient close to that of the Rene N4 substrate (7), the mechanical strain range developed in the coating is approximately equal to that of the substrate (where, $\left.\varepsilon^{\text {mech }} \equiv \varepsilon^{\text {total }}-\varepsilon^{\text {thermal }}(13)\right)$.
} 


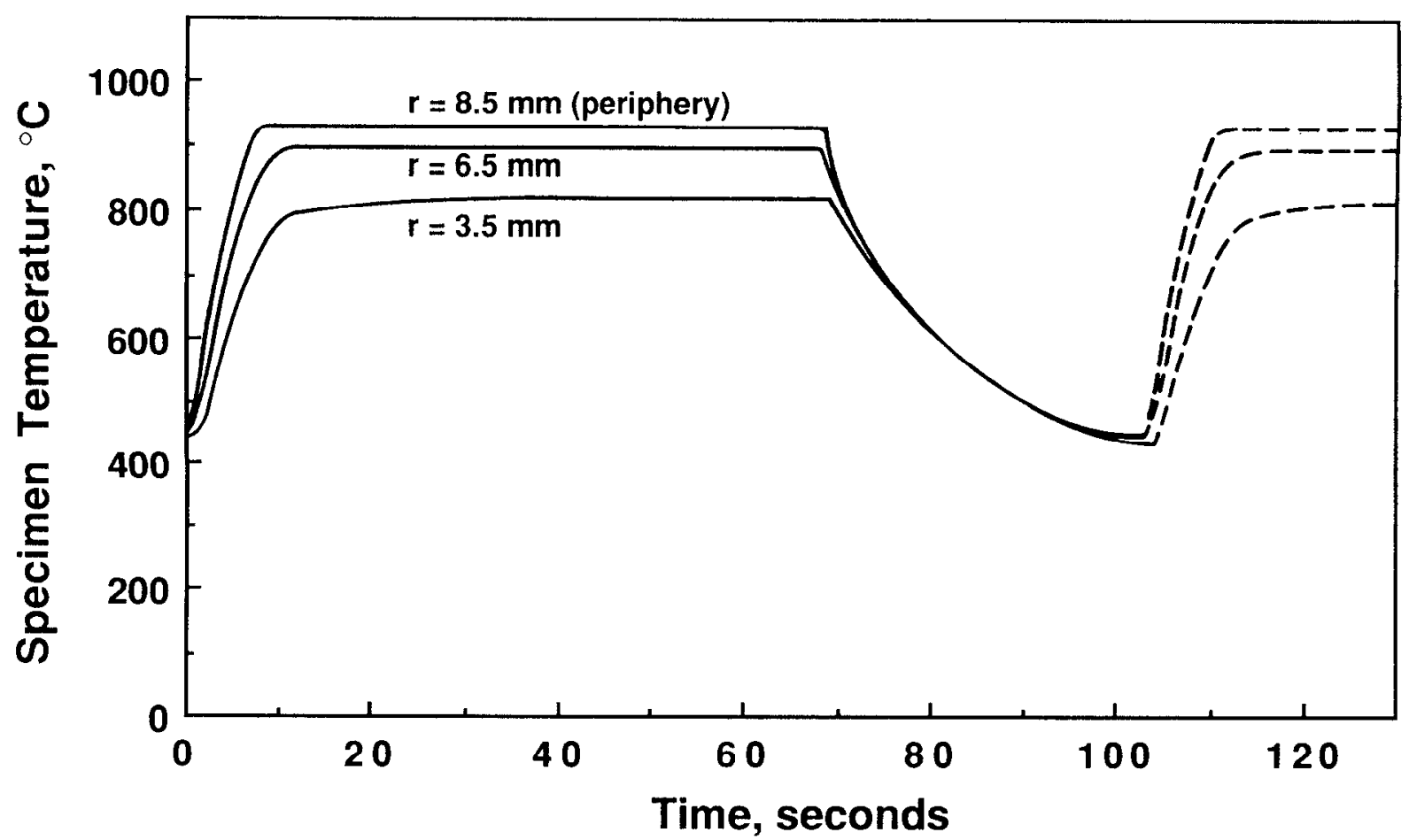

Figure 4a - Temperature history of stepped-disk specimen used in thermal-fatigue/hot-corrosion experiments. Data was obtained from thermocouples located at specimen radii of $3.5,6.5$ and $8.5 \mathrm{~mm}$.

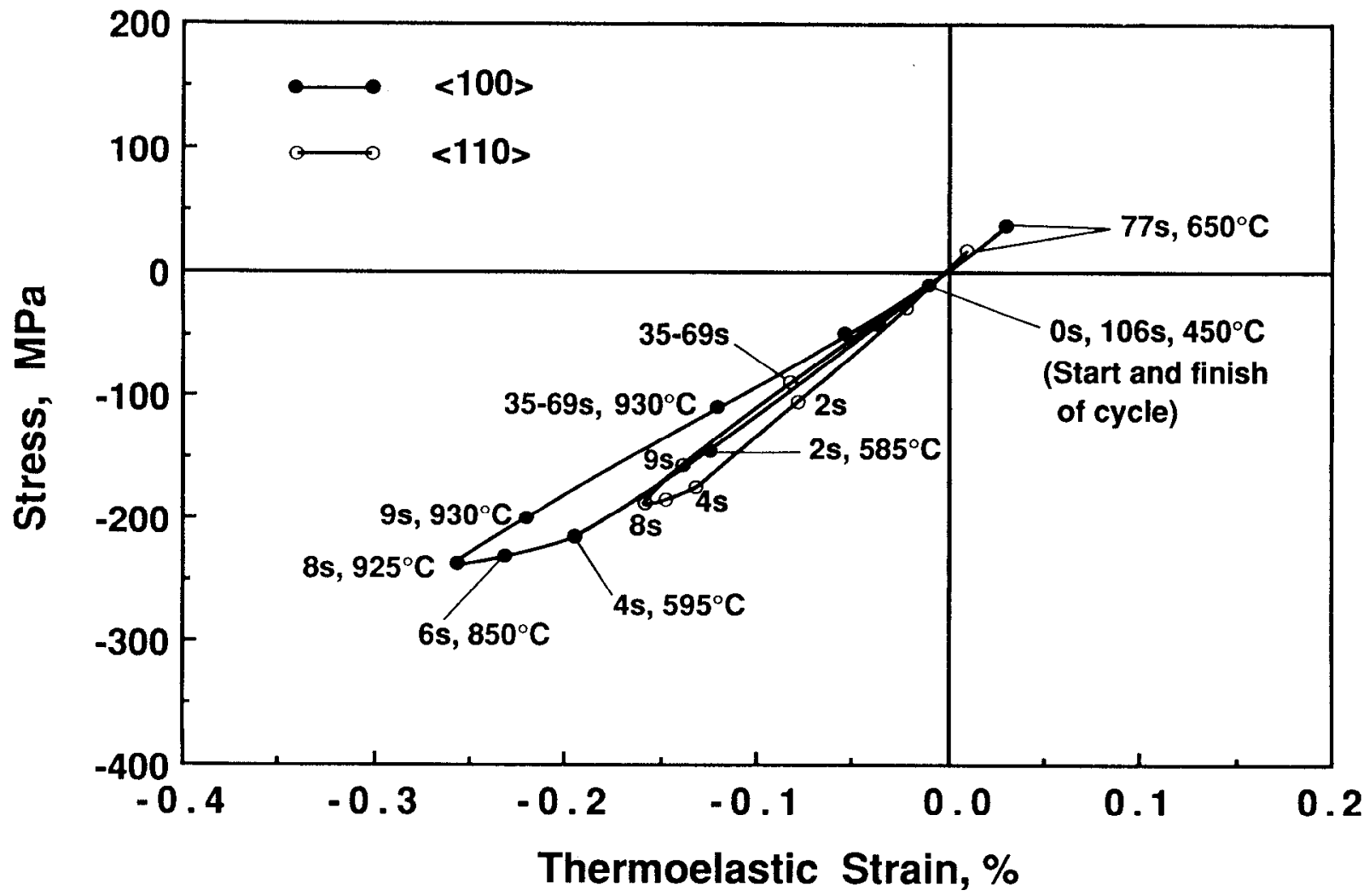

Figure $4 \mathrm{~b}$ - Circumferential stress-strain history of substrate periphery at $\langle 100\rangle$ and $\langle 110\rangle$ orientations (obtained from a thermoelastic finite element analysis $(7,10)$ ). The thermoelastic strains shown represent the "mechanical" part of the total fatigue strain, where $\varepsilon^{\text {mech }} \equiv \varepsilon^{\text {total }}-\varepsilon^{\text {thermal }}$. As discussed in the text, the mechanical strain range of the substrate and coating are approximately equal. Recent finite element analysis of stepped-disk specimens has shown that substrate creep produces a shift in mean stress towards zero, but does not significantly alter the strain range from that predicted by a thermoelastic analysis (13). 


\section{Results and Discussion}

Isothermal exposure for 100 and 200 hours at $930^{\circ} \mathrm{C}$ in the hot corrosion environment resulted in only minor surface oxidation of the aluminide coating (10). The extent of oxidation was independent of substrate orientation. After thermal fatigue testing ( 3000 and 6000 cycles, 50 and $100 \mathrm{hr}$ at $930^{\circ} \mathrm{C}$, respectively), coating oxidation, comparable in degree to that observed after isothermal exposure, was present along the low-strain $<110>$ substrate orientations $\left(\Delta \varepsilon^{\text {mech }}=0.17 \%\right)$ (Figs. 5a,c). This minor surface oxidation was in sharp contrast to the severe coating oxidation and hot corrosion attack which occurred along high-strain $<100>$ substrate orientations $\left(\Delta \varepsilon^{\text {mech }}=0.29 \%\right.$ ) (Figs. $\left.5 b, d\right)$.

Quantitative microprobe analysis of the isothermally exposed coatings showed that the chemical composition of the coating matrix was independent of substrate orientation, and similar to that found for thermally cycled coatings located along low-strain substrate orientations (10). Sulfur was not detected in either the isothermally exposed coatings or in thermally cycled coatings located along low-strain substrate orientations. Similar quantitative analysis of the coating along high-strain orientations showed extensive Al depletion had occurred, along with formation of internal Al and Ni sulfides. After 3000 fatigue cycles, sulfides were observed to a depth of approximately $30 \mu \mathrm{m}$; after 6000 cycles, sulfides penetrated to the coating/substrate interface (see sulfur X-ray map, Fig. 6).

Along low-strain orientations, the surface oxide which formed on the coating after 3000 and 6000 fatigue cycles was continuous, with a composition close to stoichiometric $\mathrm{Al}_{2} \mathrm{O}_{3}$. By contrast, along high-strain orientations the oxide scale was porous, with extensive cracking observed. For the high-strain orientations, analysis showed the presence of $\mathrm{Cr}$, Ni and Al oxides after 3000 cycles; after 6000 cycles, $W$ and Mo oxides were also found.

\section{Discussion}

Following earlier work by Elliott (14) and Steinmetz et al (15) a mechanism for the dependence of hot corrosion attack on strain history appears to be oxide cracking, followed by direct interaction between the aluminide coating and $\mathrm{Na}_{2} \mathrm{SO}_{4}$. The stress history of the surface oxide is a function of substrate orientation (see Appendix). Cracking or spallation of an initially protective oxide scale would be accentuated along high-strain $\langle 100\rangle$ substrate orientations, where the peak tensile stresses developed in a continuous $\mathrm{Al}_{2} \mathrm{O}_{3}$ layer would reach $\approx 180 \mathrm{MPa}$, versus $\approx 70 \mathrm{MPa}$ for low strain $\left.<110\right\rangle$ orientations. ${ }^{2}$ Thus, along low-strain orientations, where oxide cracking was not observed, the $\mathrm{Al}_{2} \mathrm{O}_{3}$ scale acts as a continuous barrier, preventing direct interaction between $\mathrm{Na}_{2} \mathrm{SO}_{4}$ and the coating (Fig. 7a). Along high-strain orientations, where oxide cracking is expected, $\mathrm{Na}_{2} \mathrm{SO}_{4}$ can reach the coating by penetration into oxide fissures. Subsequent reaction between $\mathrm{Na}_{2} \mathrm{SO}_{4}$ and $\mathrm{Al}$ from the coating would significantly increase the oxide ion concentration $\left(\mathrm{O}^{2-}\right)$ in the vicinity of the coating surface (Fig 7b). In the presence of a high oxide ion concentration, $\mathrm{Al}_{2} \mathrm{O}_{3}$ is unstable and will dissolve as an aluminate $(14,16): \mathrm{Al}_{2} \mathrm{O}_{3}+\mathrm{O}^{2-}=2 \mathrm{AlO}_{2}$. The corrosion front could then extend parallel to the oxide/coating interface by local dissolution of the $\mathrm{Al}_{2} \mathrm{O}_{3}$ scale in the oxide-ion enriched $\mathrm{Na}_{2} \mathrm{SO}_{4}$ melt.

The aluminate ion $\left(\mathrm{AlO}_{2}\right)$ is water soluble. Thus, if oxide dissolution (after cracking) was contributing to the corrosion process, $\mathrm{Al}$ (from $\mathrm{AlO}_{2}$ ) should be present in the water soluble corrosion products from high-strain substrate orientations. To verify this, $10^{\circ}$ sectors, centered at $\langle 100\rangle$ and $<110>$ radial lines, were removed from the specimen which had undergone 3000 fatigue cycles and analyzed for their water soluble corrosion products. The results of these analyses clearly showed the presence of $\mathrm{Al}$ in the corrosion products obtained from $<100>$ orientations, with only trace amounts detected for samples from the lower strain $<110\rangle$ orientations. In a similar analysis performed on wedges removed from the isothermally exposed specimens only $\mathrm{Na}$ and $\mathrm{S}$ were found, indicating that in the absence oxide cracking $\mathrm{Al}_{2} \mathrm{O}_{3}$ was stable in the test environment.

The mechanism described above would hold only for the initial stages of hot corrosion, within the outer $\beta$-NiAl coating layer. Once the corrosion front reaches the refractory-rich coating zone (Fig. 2, 5d), the high concentrations of $W$ and Mo in this region would significantly alter the salt chemistry, as described in detail by Goebel et al (16) and Elliott (14). Moreover, rapid oxidation of the refractory-rich precipitates would quickly consume this coating layer.

\footnotetext{
${ }^{2}$ For a similar temperature and strain history (Fig. 4a,b), oxide cracking at high-strain substrate orientations was verified by testing in air. After 500 cycles, extensive oxide cracking was observed along the periphery at $<100>$ orientations, with only a few random cracks observed at $<110>$ orientations. Oxide spalling was not observed.
} 


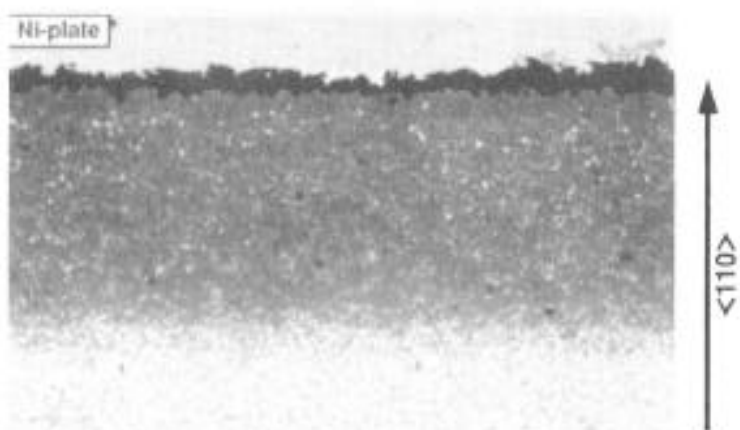

$50 \mu \mathrm{m}$

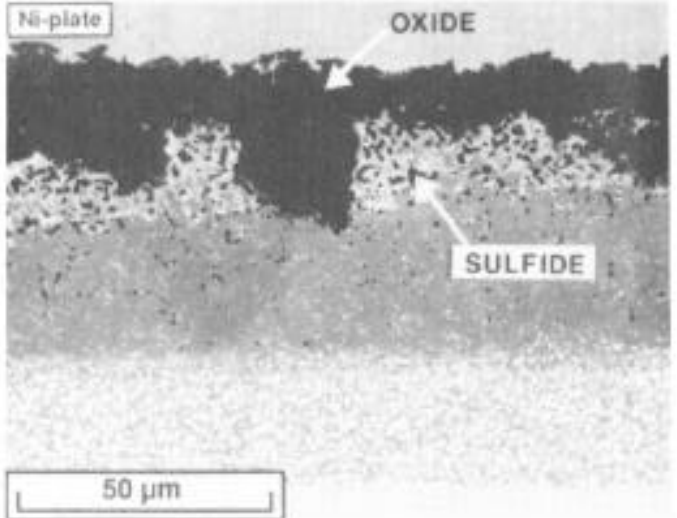

(b) $-0.26<\varepsilon<0.03 \%$
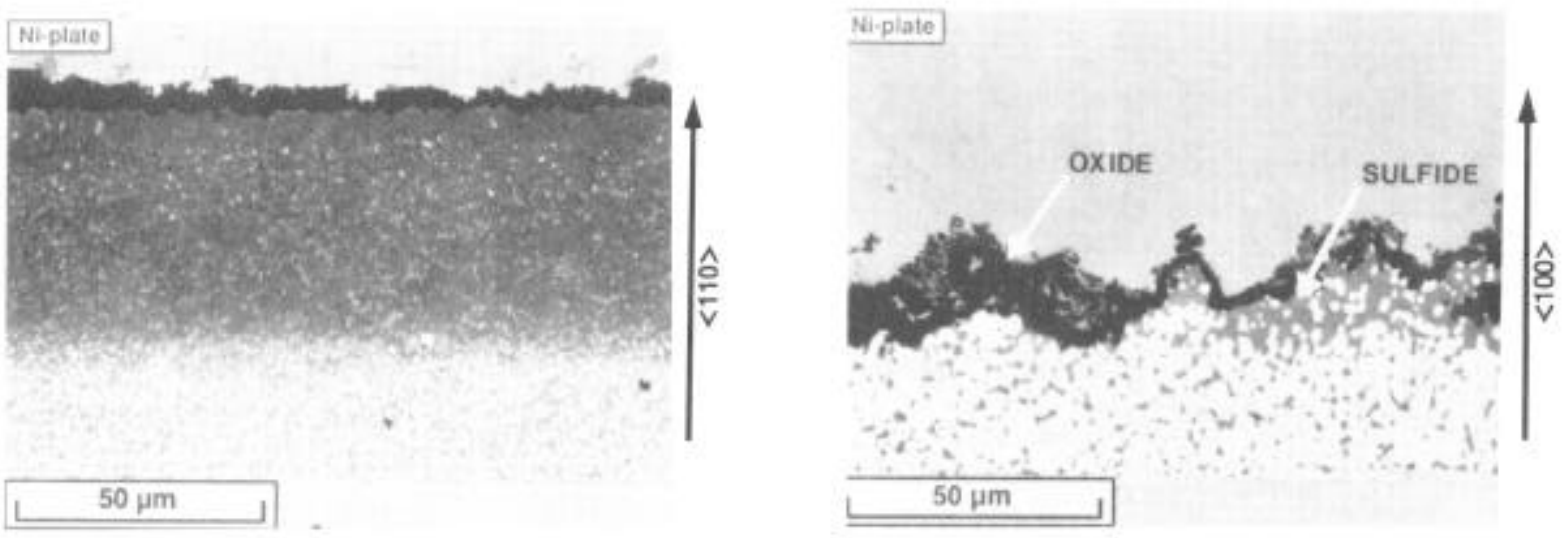

(c) $-0.16<\varepsilon<0.01 \%$

6000 cycles

(d) $-0.26<\varepsilon<0.03 \%$

Figures 5a-d - Secondary electron micrographs showing typical Ni-aluminide coating degradation along $\langle 110\rangle$ and $\langle 100\rangle$ substrate orientations after 3000 and 6000 fatigue cycles. The micrographs were taken at the specimen periphery, on a cross-section parallel to the disk face and through the specimen mid-plane. The limits of substrate strain (Fig. 4b) are given beneath each micrograph. These fatigue strains act from left to right in the plane of the micrographs.

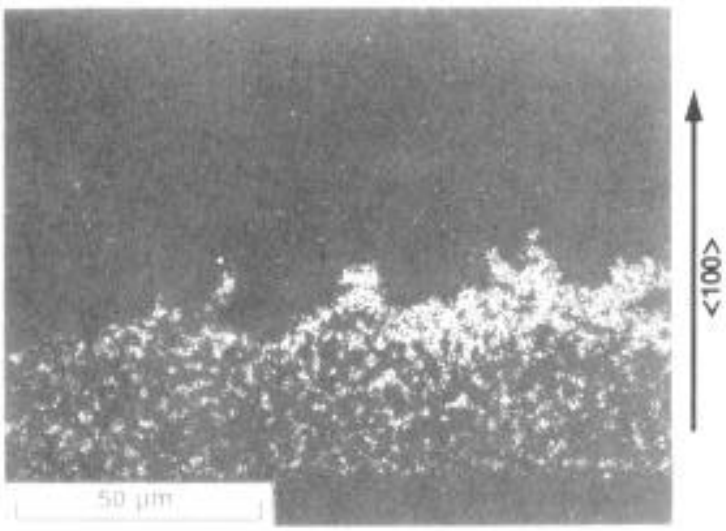

Figure 6 - X-ray image showing evidence of sulfur diffusion into coating along high strain $<100>$ orientation after 6000 fatigue cycles (companion secondary electron micrograph is shown in Fig. 5d). 


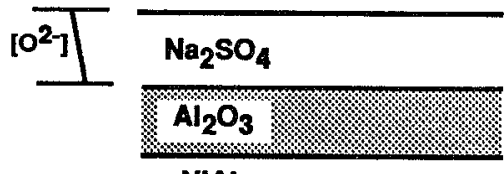

NIAl

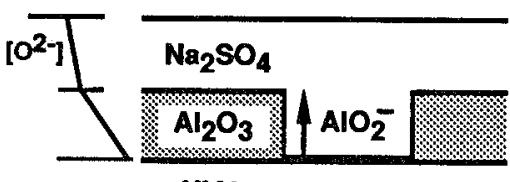

NIAI (a) Along low-strain substrate orientations, a continuous oxide scale prevents direct interaction between the coating and molten $\mathrm{Na}_{2} \mathrm{SO}_{4}$. Under these conditions, the oxide ion concentration is not sufficient to cause direct dissolution of $\mathrm{Al}_{2} \mathrm{O}_{3}$.

(b) Along high-strain substrate orientations, oxide cracking allows direct interaction between the coating and $\mathrm{Na}_{2} \mathrm{SO}_{4}$. This interaction increases the oxide ion concentration in the vicinity of the coating surface, resulting in local dissolution of $\mathrm{Al}_{2} \mathrm{O}_{3}$ and diffusion of sulfur into the coating.

Figure 7a,b - Mechanism for the strain history dependence of hot corrosion attack. For the gas composition used in the experiments, thermodynamic considerations show that $\mathrm{Al}_{2} \mathrm{O}_{3}$ would be stable beneath a thin layer of molten $\mathrm{Na}_{2} \mathrm{SO}_{4}$ at $930^{\circ} \mathrm{C}$ (the reader is referred to the stability diagram for $\mathrm{Na}-\mathrm{O}-\mathrm{S}$ given by Elliott (14)). Thus, in the absence of oxide cracking, the $\mathrm{Al}_{2} \mathrm{O}_{3}$ scale prevents interaction between the coating and environment.

It should be noted that since coating composition can influence hot corrosion attack (17), the critical strain range observed here for the acceleration of hot corrosion may be different for $\mathrm{Ni}$-aluminide coatings applied to other substrates. However, it is expected that the strain dependence of hot corrosion observed with thin $\mathrm{Ni}$-aluminide coatings will parallel that obtained for structural $\beta$-NiAl alloys subjected to similar temperature and strain histories. The results obtained indicate that evaluating hot corrosion resistance by isothermal or low-strain cyclic tests could greatly underestimate the rate of hot corrosion attack of alloys and coatings used in gas turbines, where severe thermal and strain transients are encountered. ${ }^{3}$

\section{Conclusions}

1. Hot corrosion of Ni-aluminide coatings depends critically on strain history. Only minor surface oxidation was observed after 6000 cycles between peak strains of $-0.16 \%$ at $925^{\circ} \mathrm{C}$ and $0.01 \%$ at $650^{\circ} \mathrm{C}$. However, after 6000 cycles, between peak strains of $-0.26 \%$ at $925^{\circ} \mathrm{C}$ and $0.03 \%$ at $650^{\circ} \mathrm{C}$, the coating was completely penetrated by sulfides. These results clearly show the importance of including strain history as a variable when determining the hot corrosion resistance of coatings and alloys.

2. The dependence of hot corrosion on thermal fatigue strain history can be attributed to breakdown of initially protective oxide scales by cracking, followed by direct interaction between $\mathrm{Na}_{2} \mathrm{SO}_{4}$ and the coating. This interaction results in internal sulfide formation and rapidly accelerated coating oxidation. This mechanism qualitatively explains the acceleration in hot corrosion attack observed along highly strained regions of gas-turbine airfoils.

3. Induction heating of stepped-disk fatigue specimens allows close control over specimen temperature, environment and strain history. Applying coatings to a single crystal substrate allows several coating strain histories to be studied simultaneously. However, the experimental technique is equally well suited for use with polycrystalline substrates.

\footnotetext{
3High-velocity gas burner rigs (Mach 0.3-0.8) are commonly used to determine the cyclic hot corrosion resistance of alloys and coatings used in gas turbine applications (17). However, due to the low heat transfer coefficient associated with atmospheric pressure burner rig testing, specimen heating rates may not be sufficient to reproduce the severe strain histories experienced by turbine aifoils $(5,6)$, which operate at pressures as high as 10 to 20 atmospheres. In ASTM sponsored evaluations of various burner rig test facilities (18), significant differences in hot corrosion rates were found for rigs burning similar fuel. Results obtained from the present work suggest that, in addition to salt deposition kinetics, strain history may play an important role in explaining the variation in test results observed (note that strain history is a function of gas velocity and specimen geometry).
} 


\section{Acknowledgements}

The authors would like to thank Bill Connor of General Electric Aircraft Engines for his critique of the manuscript. This work was supported by the National Science Foundation through Grant DMR 84-18718 to the Center for Materials Science and Engineering at M.I.T.

\section{Appendix: Stress-Strain History of Surface Oxide}

Although the surface oxide is in a state of biaxial stress, the peak stresses will be approximated here by a simpler 1-D analysis, which allows a more intuitive description of the important parameters controlling oxide stress. Modulus and thermal expansion data for polycrystalline $\mathrm{Al}_{2} \mathrm{O}_{3}$ were obtained from Samsonov (19) and Touloukian et al (20), respectively. Thermal expansion data for the Rene N4 substrate was obtained from Holmes et al (7).

Since the thin oxide offers negligible constraint to the substrate, the change in total oxide strain must equal the change in total substrate strain (note that the thin coating does not enter into the analysis, since it only acts as a vehicle to transfer substrate strain to the oxide). The increment in total oxide strain $\delta \varepsilon_{0 x}$ is equal to the sum of the elastic strain $\delta \varepsilon_{o x}^{e}$ and the strain due to thermal expansion of the oxide $\alpha_{o x} \delta \mathrm{T}$ :

$$
\delta \varepsilon_{0 x}=\delta \varepsilon_{o x}^{e}+\alpha_{o x} \delta T .
$$

Equating $\delta \varepsilon_{\mathrm{ox}}$ from Eq. A1 to the increment in total substrate strain $\delta \varepsilon_{\mathrm{s}}$ which, ignoring inelastic deformation*, also has only elastic $\left(\delta \varepsilon_{s}^{e}\right)$ and thermal $\left(\alpha_{s} \delta T\right)$ components, gives

$$
\delta \varepsilon_{\mathrm{ox}}=\delta \varepsilon_{\mathrm{s}}^{\mathrm{e}}+\left(\alpha_{\mathrm{s}}-\alpha_{\mathrm{ox}}\right) \delta \mathrm{T} .
$$

For a change in oxide strain given by Eq. A2 the change in oxide stress is

$$
\delta \sigma_{o x}=E_{o x} \delta \varepsilon_{o x}^{e}=E_{o x}\left[\delta \varepsilon_{s}^{e}+\left(\alpha_{s}-\alpha_{o x}\right) \delta T\right] .
$$

Due to the orientation dependence of elastic substrate strain $\delta \varepsilon_{S}^{e}$ (Fig. $4 \mathrm{~b}$ ), the oxide stress $\delta \sigma_{\text {ox }}$ is a function of substrate orientation.

Application of Eg. A3. From Eq. A3, the stress increment in the oxide $\delta \sigma_{\text {ox }}$ depends upon the relative magnitudes of the elastic $\delta \varepsilon_{\mathrm{s}}^{e}$ and thermal $\left(\alpha_{\mathrm{s}}-\alpha_{0 x}\right) \delta T$ strain components. Since the surface oxide forms primarily during the 60 s hold at $930^{\circ} \mathrm{C}$, the oxide will be stress free prior to specimen cooldown (ignoring growth strains) (10).** In the early stages of specimen cooldown from $930^{\circ} \mathrm{C}$, where $\delta \varepsilon_{S}^{e}$ is initially positive and of greater magnitude than the negative thermal strain $\left(\alpha_{s}-\alpha_{o x}\right) \delta T$, tension is produced in the oxide (note that $\alpha_{s}>\alpha_{o x}$ ). At a later stage of cooldown the situation reverses, and the negative contribution from $\left(\alpha_{s}-\alpha_{o x}\right) \delta T$ dominates, driving the oxide into compression. The substrate strain increment is largest along $\langle 100\rangle$ orientations (Fig. $4 b$ ), whereas the thermal strain increment is independent of substrate orientation."** Therefore, from Eq. A3, the oxide tension produced during cooldown will be highest at $<100>$ orientations. Peak tension develops in the oxide at approximately $800^{\circ} \mathrm{C}$ ( $\approx 180 \mathrm{MPa}$ for $<100>$ orientations and $\approx 70 \mathrm{MPa}$ for $<110>$ orientations) and decreases in magnitude with further cooling, becoming compressive at approximately $620^{\circ} \mathrm{C}$ for $\left.<100\right\rangle$ orientations and $700^{\circ} \mathrm{C}$ for $\left.<110\right\rangle$ orientations.

During heating, $\delta \varepsilon_{s}^{e}$ is negative (up to $925^{\circ} \mathrm{C}$, Fig. $4 b$ ), resulting in a negative contribution to oxide stress, whereas the thermal strain increment produces a positive contribution to the oxide stress $\left(\left(\alpha_{s}-\alpha_{O X}\right) \delta T>0\right)$ which is independent of orientation. The peak compressive stress developed in the oxide during heating would be approximately $400 \mathrm{MPa}\left(720^{\circ} \mathrm{C}\right)$ at $<100>$ orientations and $350 \mathrm{MPa}\left(600^{\circ} \mathrm{C}\right)$ at $<110>$ orientations. Since oxide growth stresses and inelastic oxide behavior are negligible, the oxide stress and strain must return to zero at the completion of a full cycle $\left(930^{\circ} \mathrm{C}\right.$ to $\left.930^{\circ} \mathrm{C}\right)$.

It is important to note that had the oxide formed on an unstrained substrate, such as might occur with cyclic corrosion testing in an electric furnace, the oxide stress would remain compressive during the entire temperature cycle (this can be seen by setting $\delta \varepsilon_{s}^{e}=0$ in Eq. A3). Furthermore, the magnitude of the compressive oxide stress would be independent of substrate orientation.

"Note that, for this case, $\delta \varepsilon_{s}^{\text {mech }}=\delta \varepsilon_{s}^{e}$. Recent finite element analysis has shown that substrate creep leaves the strain limits largely unaffected (13); therefore, its omission does not alter the results of the present analysis.

"Increments are calculated from the end of the steady state hold at $930^{\circ} \mathrm{C} \mathrm{(Fig.} 4 \mathrm{~b}$ ).

"*For cubic materials, thermal expansion is isotropic. 
1. R. E. Fryxell and G. E. Leese, "Effects of Surface Chemistry on Hot Corrosion Life," NASA CR-179471 (1986).

2. J. J. Grisik, R. G. Miner and D. J. Wortman, "Performance of Second Generation Airfoil Coatings in Marine Service," Ihin Solid Films, 73 (1980) 397-406.

3. Y. Bourhis and C. St. John, $" \mathrm{Na}_{2} \mathrm{SO}_{4}$ and $\mathrm{NaCl}$-Induced Hot Corrosion of Six Nickel-Base Superalloys," Oxidation of Metals, 9 (6) (1975) 507-526.

4. M. N. Richards and J. Stringer, "Some Aspects of the Hot Corrosion of Cobalt-Base Alloys," British Corrosion Journal, 8 (1973) 167-173.

5. A. Kaufman and R. H. Hafford, "Engine Cyclic Durability Analysis and Materials Testing, NASA Technical Memorandum 83577 (1984).

6. E. D. Thulin, D. C. Howe and I. D. Singer, "Energy Efficient Engine: High Performance Turbine Detailed Design Report," NASA Report CR-165608 (1982).

7. J. W. Holmes, F. A. McClintock, K. S. O'Hara and M. E. Conners, "Thermal Fatigue Testing of Coated Monocrystalline Superalloys," Low Cycle Fatique, ASTM STP 942, H. D. Solomon et al., eds. (Philadelphia, PA: American Society for Testing and Materials, 1988), 672-691.

8. G. W. Goward and D. H. Boone, "Mechanisms of Formation of Diffusion Aluminide Coatings on Nickel-Base Superalloys," Oxidation of Metals, 3 (5) (1971) 475-495.

9. J. W. Holmes and F. A. McClintock, "The Chemical and Mechanical Processes of Thermal Fatigue Degradation of an Aluminide Coating," accepted for publication in Metallurgical Transactions A.

10. J. W. Holmes, "Thermal Fatigue Oxidation and $\mathrm{SO}_{2}$ Corrosion of an Aluminide Coated Superalloy," (Doctoral thesis, Department of Materials Science and Engineering, Massachusetts Institute of Technology, Cambridge, Massachusetts, September 1986). Available through: Micro-reproduction Laboratory, MIT, 77 Massachusetts Avenue, Cambridge, MA 02139.

11. A. Taylor and R. W. Floyd, "The Constitution of Nickel-Rich Alloys of the Nickel-Chromium-Aluminum System," Journal of the Institute of Metals, 81 (1952) 451-464.

12. J. Davies and P. Simpson, Induction Heating Handbook, (London: McGraw Hill, 1979) Chapter 12.

13. E. S. Busso and F. A. McClintock,"Stress-Strain Histories in Coatings on Single Crystal Specimens of a Turbine Blade Alloy," accepted for publication in International Journal of Solids and Structures.

14. J. F. Elliott, "Chemistry of Hot Corrosion," Solid State Chemistry of Energy Conversion and Storage, eds. John B. Goodenough and M. Stanley Whittingham (Columbus Ohio, American Ceramic Society, 1977), 225-239.

15. P. Steinmetz. at al, "Hot Corrosion of Aluminide Coatings on Nickel-Base Superalloys," High Iemperature Protective Coatings, ed. S.C. Singhal (Warrendale, PA: The Metallurgical Society, 1982) 135-157.

16. J. A. Goebel, F. S. Pettit and G. W. Goward, "Mechanisms for the Hot Corrosion of Nickel Base Superalloys," Metalluraical Transactions, 4 (1973) 261-278.

17. R. E. Fryxell and G. E. Leese, "Role of Diffusion Zone Structure in the Hot Corrosion of Aluminide Coatings on Nickel Based Superalloys," Surface and Coatings Technology, 32 (1987) 97-110.

18. Hot Corrosion Task Force for ASTM Gas Turbine Panel: Round Robin Test, (Philadelphia, PA: American Society for Testing and Materials, 1970).

19. G. V. Samsonov, The Oxide Handboek, (New York: Plenum, 1973), pg. 183.

20. Y. S. Touloukian et al, Thermophysical Properties of Matter, Vol. 13, (New York: Plenum, 1979). 